\title{
Transformation of Snow White to Ugly Duckling: Neurobehavioral Impact of Childhood Craniopharyngioma
}

\author{
Suravi Patra ${ }^{1}$ Ashok K. Mahapatra ${ }^{2}$ \\ ${ }^{1}$ Department of Psychiatry, All India Institute of Medical Sciences, \\ Bhubaneswar, Odisha, India \\ 2 Department of Neurosurgery, All India Institute of Medical Sciences, \\ Bhubaneswar, Odisha, India
}

\begin{abstract}
Address for correspondence Suravi Patra, MD, Department of Psychiatry, All India Institute of Medical Sciences, Bhubaneswar, Odisha, India (e-mail: patrasuravi@gmail.com).
\end{abstract}

Indian J Neurosurg 2015;4:114-116.

\author{
Abstract \\ Keywords \\ - childhood \\ craniopharyngioma \\ - neurobehavioral \\ disorders \\ - management
}

Neurobehavioral problems are seen in children with craniopharyngiomas both before and after treatment, which cause significant morbidity. Behavioral problems include aggressive behavior, hyperphagia, impaired school performance, and poor social behavior. These children have impairment in psychosocial functioning and have a poor quality of life. Family members face a lot of difficulty in managing these difficulties. These behavioral problems are difficult to manage even by the health-care givers as there are no evidence-based treatment protocols. Behavioral therapy has been documented to be of benefit in certain cases, and the authors here also demonstrate the usefulness of behavior therapy in managing the behavioral problems of a child who had a successful gross total excision of craniopharyngioma with an otherwise uneventful postoperative course.

\section{Introduction}

Craniopharyngiomas are locally invasive embryonic crest cell tumors located in the sellar or suprasellar regions of the brain. About 30 to $40 \%$ of these rare tumors present in the childhood age group of 5 to 15 years. ${ }^{1}$ Neurobehavioral manifestations are due to proximity to vital neurovascular regions of the brain or due to surgery and radiotherapy. ${ }^{2}$ The resultant poor functioning and impaired quality of life adversely affect recovery and pose a challenge to the caregivers as well as the health care providers. ${ }^{3}$ Though not uncommon, neurobehavioral impact of childhood craniopharyngioma has not been reported from India till date.

The authors present a case of postoperative childhood craniopharyngioma with neurobehavioral, emotional, and social dysfunction that was managed with behavioral intervention.

received

June 28, 2014

accepted

May 14, 2015

published online

July 28, 2015
DOI http://dx.doi.org/ $10.1055 / \mathrm{s}-0035-1558964$ ISSN 2277-954X.

\section{Case History}

An 8-year-old typically developing female child who had undergone gross total excision and ventriculoperitoneal (VP) shunting of suprasellar cystic and calcified craniopharyngioma with obstructive hydrocephalus (-Figs. 1A-C and 2) 2 months back was brought by her mother for follow-up when she shared the difficulties she was facing while managing her.

The child had become demanding and aggressive in her behavior toward her family members following the surgery. She had become physically inactive and would not read books, play, draw, or color which she used to like earlier. She would remain drowsy in daytime and would have trouble falling asleep at night. She had stopped attending her classes (third grade) and her mother used to take her along to eighth grade that she taught. The child liked the preferential treatment she received in the classroom and would refuse to go to her class.
License terms of India 

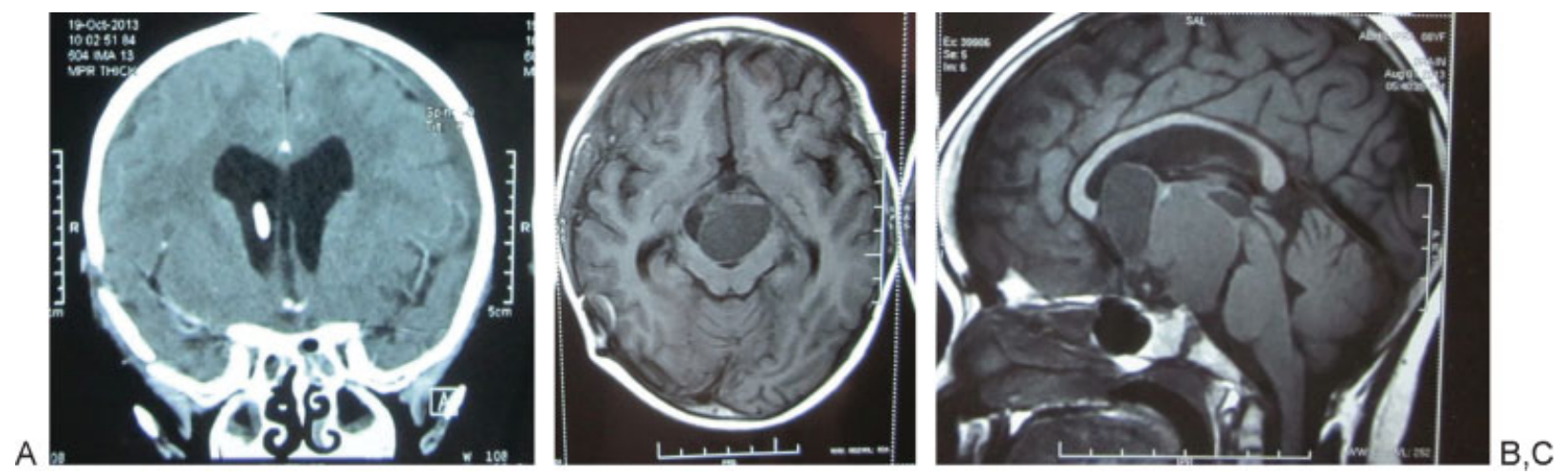

Fig. 1 (A) T1 axial hypointense suprasellar mass causing brainstem compression. (B) T2 axial hyperintense suprasellar lobulated mass. (C) T1 contrast sagittal image shows two components of the mass hypo- and isointense with a fluid level causing brainstem compression.

At home her behavior was becoming increasingly difficult for the mother to manage. She would start shouting and would even hit when her demands were not instantly met. She had been becoming more violent toward her sister of $2 \frac{1}{2}$ years. She would call her and would then hit or push her for no apparent reason. The frequency of aggressive behavior increased from two to three times a day to eight to nine times a day. Her food habits had changed; she had started taking more sweets and cold drinks, and had started putting on weight; and her mother was finding it difficult to restrict her intake of sweets.

The patient also had frequent complains of pain in the stomach. She would also remain irritable and would scream on being asked to do anything. She had become intolerant to sounds or voices of people.

Her aggressive behavior had started when she was weaned off the ventilator in the postoperative period. She

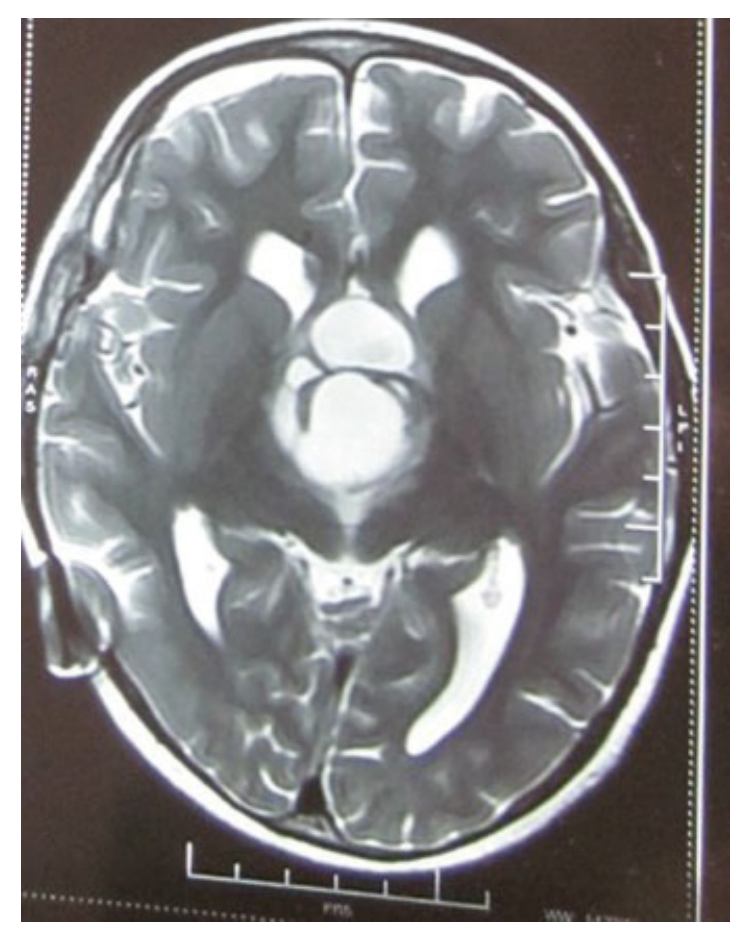

Fig. 2 Postoperative CT scan of the brain in coronal section shows shunt in situ with removal of mass. would scream and hit the nurses while they would attempt to administer injections or draw blood sample. Her aggressive behavior persisted after discharge when she attempted to throw her 2-year-old cousin from the balcony on finding her box of crayons with him. Her recent behavior of attempting to hit a student of eighth grade was found excessively worrying for her mother.

Formal neuropsychiatric evaluation was performed to assess her cognitive, emotional, social, and psychological functioning. Modified Child Mini Mental Status Scale was used for assessment of cognitive functioning. ${ }^{4}$ The scale was validated for use in 3- to 14-year-old Indian children as a cognitive screening instrument. The test includes five subtests for assessment of orientation, attentionconcentration, registration, recall, and language. The cutoff score for cognitive impairment in children aged 6 to 8 years is 28 . The index patient scored 33 out of 37 , which implied average cognitive functioning for that age.

Pediatric Symptom Checklist (PSC) was used to assess her psychosocial functioning and reflects parents' impressions of their children's psychosocial functioning. The validity of PSC in measuring childhood dysfunction is found to be similar to Child Behavioral Checklist (CBCL). ${ }^{5}$ It consists of 35 items that are rated as "never," "sometimes," or "often" present (scored 0,1 , and 2, respectively). Item scores are summed and the total score is recoded into a dichotomous variable indicating psychosocial impairment. For children aged 6 through 16 years, the cutoff score was 28 or higher. The child had a total score of 42 in the PSC, which indicated impairment.

Her Childhood Global Assessment of Functioning score was 35 , which implied that she had major impairment in functioning in several areas.

Pediatric Quality of Life Inventory version 4.0 (parent version) was used to assess her Quality of life. ${ }^{6}$ The scale is a generic version to assess quality of life in children with 23 items in four domains: physical functioning, emotional functioning, social functioning, and school functioning. The Mean PedsQL score was 18.47, which was much lower than the normative standard of 87.05 for her age group.

Intervention. After functional behavioral assessment, differential reinforcement of adaptive behavior was started. It was decided to make classroom environment of third 
grade more appealing to her. She was advised to spend few morning hours in the third grade and to do her homework in the afternoons. Star charting of the behavior was done and rewards were set. This was done to engage her in the daytime in activities so as to make her sleep cycle as close to normal as possible. Mother reports of some improvement in her behavior after starting the suggested changes and brings her for regular follow-up.

\section{Discussion}

Western literature predicts that about one-third to half of patients with treated craniopharyngioma suffers from neurobehavioral, social, and emotional dysfunction. ${ }^{7}$ Manic symptoms have been reported in a child presenting with craniopharyngioma in Indian literature, but no systematic study is available on neurobehavioral problems. ${ }^{8}$

There are multifactorial causes for neurobehavioral disturbances seen in pediatric craniopharyngioma: tumor size and location, degree of hypothalamic involvement, hypopituitarism, hormonal imbalances, obesity, hydrocephalus, and surgical interventions per se. ${ }^{9}$ In this case, proximity of the tumor to hypothalamus and hydrocephalus with VP shunt in situ and obesity (body mass index $[\mathrm{BMI}]=25.14$ ) might be contributory to her behavior.

Behavior therapy has been reported to be successfully used in the management of these symptoms that we used in this case. $^{10}$

\section{Conclusion}

Regular assessment and monitoring of neurobehavioral, emotional, and social functioning of children with craniopharyngioma can help devise appropriate psychiatric interventions in the difficult-to-manage cases.
Conflict of Interest

None.

\section{References}

1 Müller HL. Craniopharyngioma-a childhood and adult disease with challenging characteristics. Front Endocrinol (Lausanne) 2012;3(3):80

2 Müller HL. Childhood craniopharyngioma. Pituitary 2013;16(1): 56-67

3 Zada G, Kintz N, Pulido M, Amezcua L. Prevalence of neurobehavioral, social, and emotional dysfunction in patients treated for childhood craniopharyngioma: a systematic literature review. PLoS ONE 2013;8(11):e76562

4 Jain M, Passi GR. Assessment of a modified Mini-Mental Scale for cognitive functions in children. Indian Pediatr 2005;42(9): 907-912

5 Jellinek MS, Murphy JM, Little M, Pagano ME, Comer DM, Kelleher KJ. Use of the Pediatric Symptom Checklist to screen for psychosocial problems in pediatric primary care: a national feasibility study. Arch Pediatr Adolesc Med 1999;153(3): 254-260

6 Varni JW, Seid M, Kurtin PS. PedsQL 4.0: reliability and validity of the Pediatric Quality of Life Inventory version 4.0 generic core scales in healthy and patient populations. Med Care 2001;39(8): 800-812

7 Laffond C, Dellatolas G, Alapetite C, et al. Quality-of-life, mood and executive functioning after childhood craniopharyngioma treated with surgery and proton beam therapy. Brain Inj 2012; 26(3):270-281

8 Prusty GK, Subramanya, Hemalatha V, Narayanan HS. Craniopharyngioma presenting as 'mania'-case report. Indian J Psychiatry 1982;24(3):305-306

9 Dolson EP, Conklin HM, Li C, Xiong X, Merchant TE. Predicting behavioral problems in craniopharyngioma survivors after conformal radiation therapy. Pediatr Blood Cancer 2009;52(7): 860-864

10 Hammond JL, Hall SS. Functional analysis and treatment of aggressive behavior following resection of a craniopharyngioma. Dev Med Child Neurol 2011;53(4):369-374 